\title{
Perioperative airway management in the case of severe tracheal narrowing and deviation caused by multinodular goitre: case report
}

Yabasin Iddrisu Baba ${ }^{1,2^{*}}$, Abass Adam ${ }^{3}$, Sam-Awortwi Wilfred ${ }^{4}$, Mohammed Mohammed Ibrahim $^{5}$, Andreas Reith ${ }^{6}$, Yangyuoru Jacob Bagviel Phu Du Nguyen ${ }^{7}$, Sylvanus Kampo ${ }^{8}$ and Juventus Benogle Ziem ${ }^{5}$

*Correspondence: farai46@yahoo.com (1) CrossMark

'Department of Anesthesia, Tamale Teaching Hospital, Ghana.

${ }^{2}$ Department of Anesthesiology, First Affiliated Hospital of Dalian Medical University, 9 Western Section, Lvshun South Road, Lvshun Dalian Liaoning, P. R. China.

${ }^{3}$ Department of Surgical Sciences, School of Medicine \& Health Sciences, UDS, Tamale Ghana.

${ }^{4}$ Department of Anesthesia, Komfo-Anokye Teaching Hospital, Kumasi, Ghana.

${ }^{5}$ Department of Laboratory Science, School of Medicine \& Health Sciences, UDS, Tamale, Ghana.

${ }^{6}$ Anaesthesia Group Practice Anaesthesieteam Ulm, Germany.

${ }^{7}$ Department of General, Visceral and Vascular Surgery, Karl-Olga-Krankenhaus. Stuttgart, Germany.

${ }^{8}$ Department of Anesthesia, School of Medicine \& Health Sciences, UDS, Tamale, Ghana.

\begin{abstract}
Background: Worldwide, endemic goiter is prevalent and is often caused by inadequate iodine intake. On the other hand, iodine may not be deficient in some parts of the world, yet goiters still occur due to the presence of goitrogens in the diet which eventually leads to the thyroid gland enlargement by interfering with normal production of thyroid hormone. In Sub-Saharan Africa, iodine deficiency is widespread and is of public health concern. However, limited diagnostic and management possibilities in this area often result in long standing goiters which eventually develops into large goiters that consequently compress the airway.

Case presentation: A 74-year-old woman diagnosed with multi nodular goiter was anesthetized for sub-total thyroidectomy. The goiter was large and multi nodular in nature, pushing the trachea to the left side of the neck. This subsequently led to tracheal compression, narrowing, and deviation. During induction of general anesthesia, intubation using flexible fibreoptic bronchoscopy techniques was impossible. Tracheal intubation was achieved via tracheostomy using size 7-mm cuffed endotracheal tube. We present this case at length and describe how the airway was secured during and after surgery.

Conclusion: Airway management for thyroidectomy involving large goiters with severely compromised airways could be considered for tracheostomy in most hospitals in developing countries where advanced anesthesia equipment are not readily available.
\end{abstract}

Key words: Multinodular goiter, airway, thyroidectomy, intubation, tracheostomy

\section{Background}

Globally, endemic goiter is prevalent and is usually caused by iodine deficiency in the diet $[1,2]$. In some parts of the world, iodine may not be deficient yet goiters may still occur due to the presence of goitrogens in the diet which cause thyroid gland enlargement by interfering with the normal production of thyroid hormones [3]. In Sub-Saharan Africa, iodine deficiency is widespread and is of public health concern. However, limited diagnostic and management possibilities in this area often result in long standing goiters eventually developing into large goiters that consequently compress the airway [4].

Thyroidectomy is indicated for the management of large goiters with the objective of offering quick and effective release of compressive symptoms. Compression and deviation of the trachea caused by these large goiters can interfere with intubation during general anesthesia. To avoid airway crisis and consequent respiratory embarrassment, proper airway management during anaesthesia should be ensured [5-7]. Preoperative anesthetic assessment often diagnoses a difficult intubation $[7,8]$.

Anesthesia for head and neck surgeries can present with challenges because the limited airway area is shared between the anesthesiologist and the surgeon [9]. In such cases, induction of general anesthesia leads to difficulties in endotracheal intubation and even facemask ventilation [10]. In such difficult circumstances, it is reasonable to device alternatives in airway management.

This case report describes the management of compromised airway due to multinodular goiter during thyroidectomy in a tropical hospital of Ghana.

\section{Case report}

The case is a 74 year old woman diagnosed with multi nodular goiter with severe tracheal deviation and narrowing. The 
patient first noticed an anterior neck swelling over 10 years which progressively increased in size over the years. Over a six month period, she developed dyspnea which was worse in the supine position and improves in the prone, right-lateral or sitting positions. Later, she developed dysphagia for solid foods and hoarseness of voice. She was a known hypertensive in a steady state with no other known systemic disease.

Physical examination revealed an elderly woman who was severely obese $\left(\mathrm{BMI}=35.2 \mathrm{~kg} / \mathrm{m}^{2}\right)$. She talks and breaths spontaneously without difficulties in the standing and sitting positions but develops stridor and severe dyspnea in the spine position. The blood pressure was $143 / 69 \mathrm{mmHg}$, heart rate 75 beats per minute and regular in the sitting position. Chest auscultation revealed normal vesicular breath sounds with no abnormal or added sounds. Other systemic examination did not reveal any abnormality. She had an obvious anterior neck swelling which was multinodular in nature and measured approximately $12 \mathrm{~cm} \times 8 \mathrm{~cm}$ broadly extending to the right lateral aspect of the neck. The thyromental distance could not be measured due to the extensively enlarged swelling. Even though the lateral neck mobility was not restricted, neck extension was severely impaired. Mouth opening was adequate, upper incisors intact with Mallampati grade 4 upper-airway. Figure 1 is a pictorial view of the anterior neck showing the enlarged multinodular goiter.

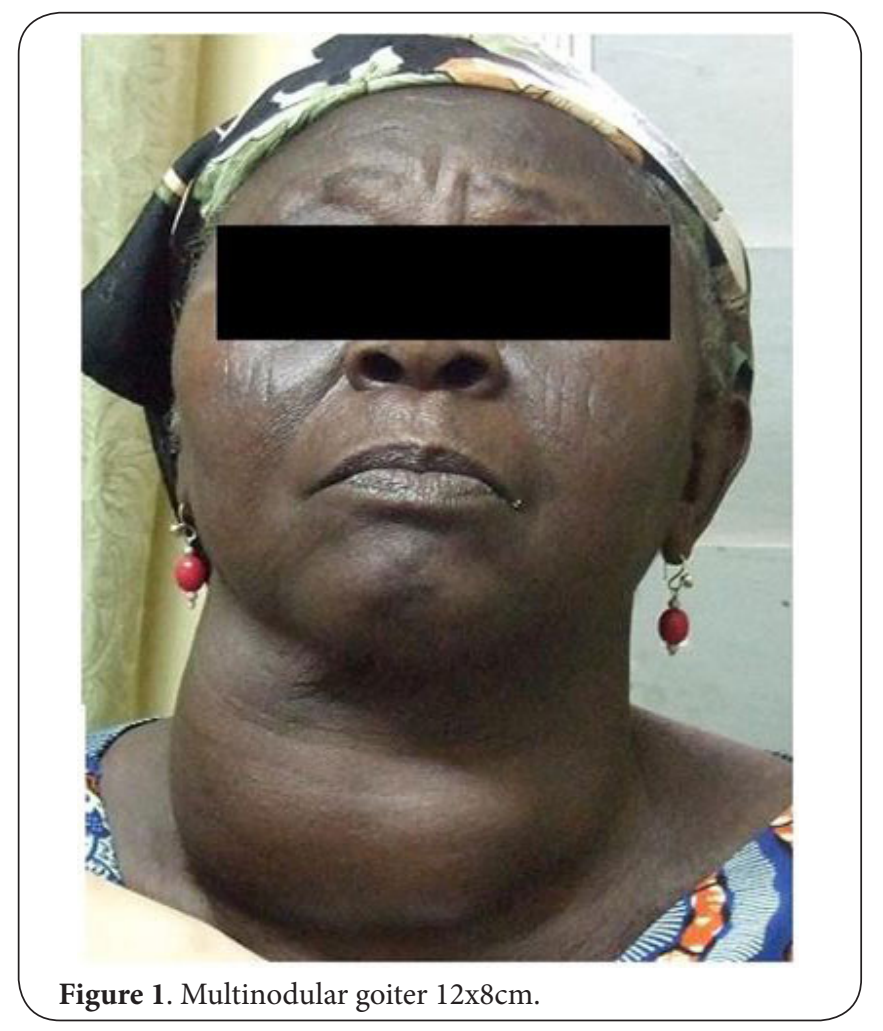

Chest and neck x-ray showed a displaced trachea to the left lateral side of the neck. Figure $\mathbf{2}$ is an antero-posterior x-ray

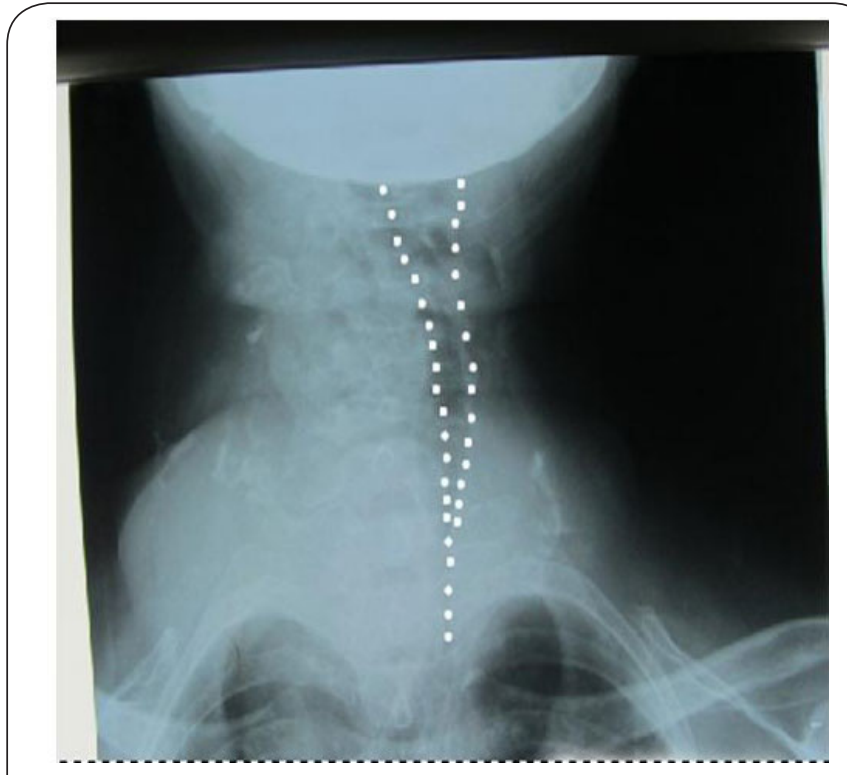

Figure 2. Anterior-posterior neck and chest X-Ray showing left sided deviation of trachea.

of the neck and thoracic inlet of the chest showing severe narrowing and deviation of the trachea to the left.

Routine laboratory investigations showed normal Full Blood Count (FBC) and Clotting profile. Blood Urea, Electrolyte (BUE), Createnin and Thyroid Functioning Test (TFT) were also normal. Multinodular goiter with compromised airway was diagnosed and patient scheduled for subtotal thyroidectomy.

\section{Airway management}

To secure the airway for ventilation, awake fiberoptic intubation was attempted and failed due to severe trachea deviation. The situation and the remaining alternatives under the limited conditions of a developing country were then extensively discussed within the team. After careful consideration and appreciation of the fact that the patient's dyspnea due to the growing and compressing goiter had increased over the past few months, a decision was made to undertake an elective tracheostomy-provided that a Laryngeal Mask Airway could be inserted effectively and that the patient could be ventilated sufficiently via Laryngeal Mask. The fact that an experienced specialist for goiter surgery and a specialist for maxillofacial and neck surgery were both part of the surgical team contributed to taking this decision.

The patient was put in the supine position, preoxyginated with $100 \%$ oxygen via face mask for 15 minutes and intravenously anaesthetized with $100 \mathrm{mcg}$ Fentanyl and intravenous propofol $150 \mathrm{mg}$. After ceasing of spontaneous respiration, controlled ventilation via face mask was performed without problems. Anesthesia was then deepened with $100 \mathrm{mcg}$ of Remifentanil and maintained using $1 \%$ propofol at $5 \mathrm{mg} / \mathrm{kg} / \mathrm{h}$ and remifentanyl $0.5 \mathrm{mcg} / \mathrm{kg} / \mathrm{min}$ via the intravenous route. Throughout the attempts at securing the airway, arterial 
oxygen saturation was maintained between $95 \%-100 \%$ by face mask ventilation. Also $8 \mathrm{mg}$ of dexamethasone was administered intravenously to minimize laryngeal and tracheal inflammation. Subsequently, size 4 laryngeal mask airway (LMA) was uneventfully inserted through the oral cavity into the hypopharynx and the cuff inflated with $30 \mathrm{ml}$ of air to secure it. The breathing circuit of the anaesthesia machine was connected to the LMA and the chest auscultated to ensure that the lungs were adequately and equally ventilated. In order to avoid surgical complications due to the large nature of the goiter, the tracheostomy procedure was carefully performed and lasted 30 minutes. The trachea was finally intubated through the tracheostomy stoma using a size 7 $\mathrm{mm}$ cuffed endotracheal tube (first). The endotracheal tube was connected to the breathing circuit of the anaesthetic machine and adjusted until ventilation was adequate and equal bilaterally. In order to prevent aspiration of gastric contents into the trachea, the cuff was inflated with $10 \mathrm{ml}$ of air and the endotracheal tube secured with surgical sutures (Figure 3). The patient was ventilated with $100 \%$ oxygen throughout the tracheostomy procedure. Subsequently, the LMA cuff was deflated and the LMA was gently removed. Thyroidectomy proceeded normally and uneventfully.

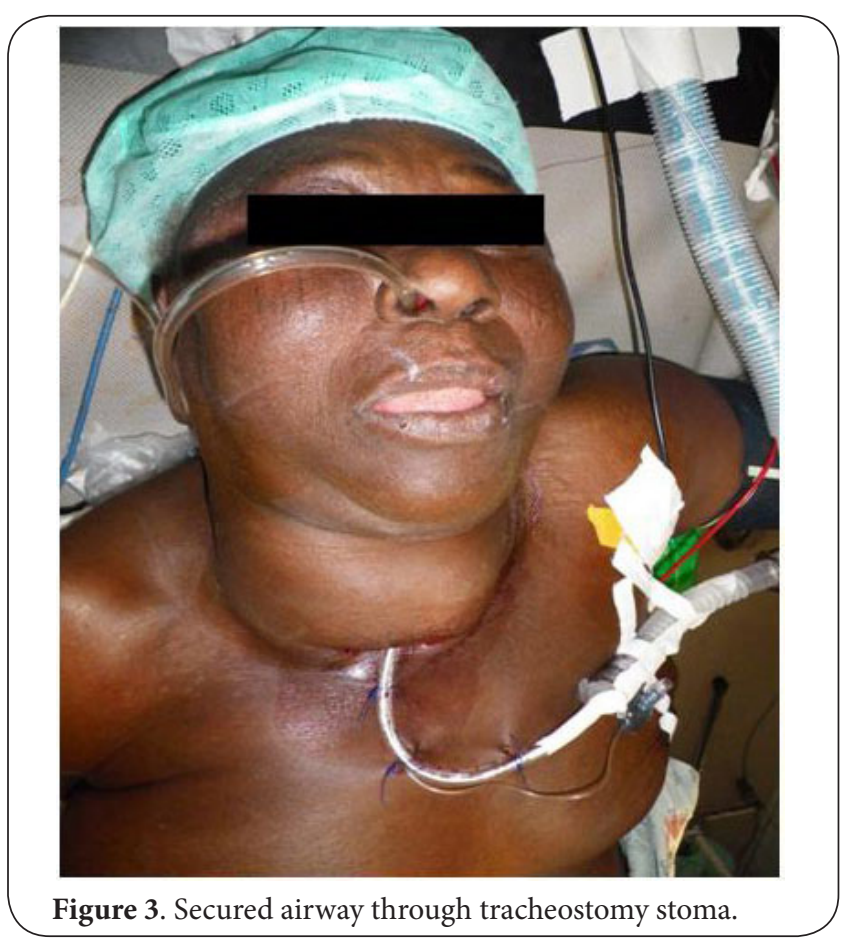

Following a successful subtotal thyroidectomy, a sterile gumelastic bougie was inserted into the trachea through the tracheostomy stoma and advanced in retrograde direction into the oral cavity (Figure 4). Through the oral cavity, another (second) sterile cuffed endotracheal tube size $7 \mathrm{~mm}$ was threaded over the gum-elastic bougie and gently passed

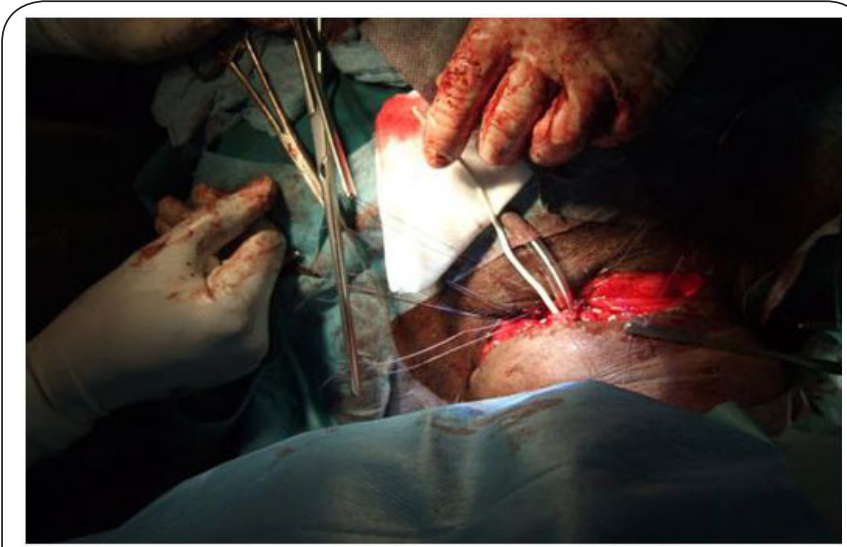

Figure 4. Introduction of gum elastic bugie into the oral cavity from the tracheostomy stoma.

into the trachea (Figure 5). After the surgeon had secured the distal end of the transoral tube with a surgical clamp the cuff of the first endotracheal tube was deflated and removed through the tracheostomy stoma. The second endotracheal tube was advanced beyond the tracheostomy stoma, the cuff inflated and the tube connected to the breathing system. The tracheostomy stoma and the entire surgical wound were closed in layers after securing homeostasis. Bronchoscopy was done through the endotracheal tube to observe the visible part of the airway distal to the tube for possible bleeding and to inspect the visible tracheal rings for tracheomalacia. The bronchoscopic inspection of the airway remained normal. So it was decided to proceed towards emergence of anaesthesia and towards extubation of a fully awake patient. After stopping propofol infusion and reducing Remifentanil the patient started with spontaneous respiration, remaining assisted for a period of $20 \mathrm{~min}$ by assisted ventilation in a 45 degree upper body elevated position, under a persisting sedative dose of $0.04 \mathrm{mcg} / \mathrm{kg} / \mathrm{min}$ Remifentanil in order to prevent tracheal irritation by the endotrachel tube. Five minutes after stopping Remifentanil-Infusion the patient was extubated fully awake with all protective airway reflexes. After extubation, the patient's ventilation was still assisted by anaesthesia face mask with $\mathrm{FiO}_{2}$ of 0.3 for five more minutes, applying slight positive pressure in order to prevent atelectasis. The patient was then transferred to the recovery ward and maintained spontaneous respiration with $4 \mathrm{~L} / \mathrm{min}$ oxygen via face mask (Figure 6). Postoperative anaesthesia care remained uneventful. All vital signs remained normal and the patient was monitored in the recovery ward for 24 hours.

\section{Discussion}

In many developing countries, multinodular goiters are caused by dietary iodine deficiency or goitrogens. Some of these goiters are long standing and may increase in size to compromise the airway. Thyroidectomy is indicated with the aim of securing the airway to avoid respiratory distress. 


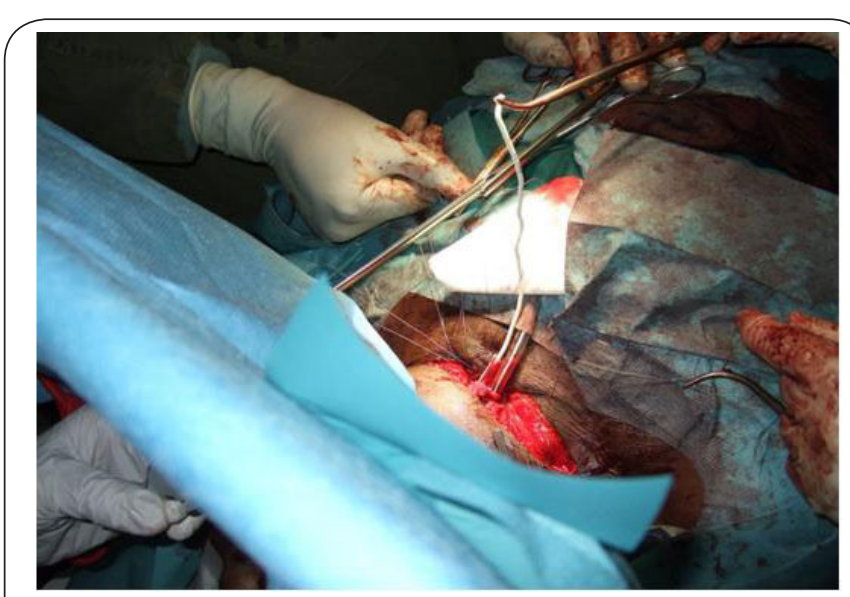

Figure 5. Endotracheal tubes exchange prior to closure of tracheostomy stoma and the entire wound.

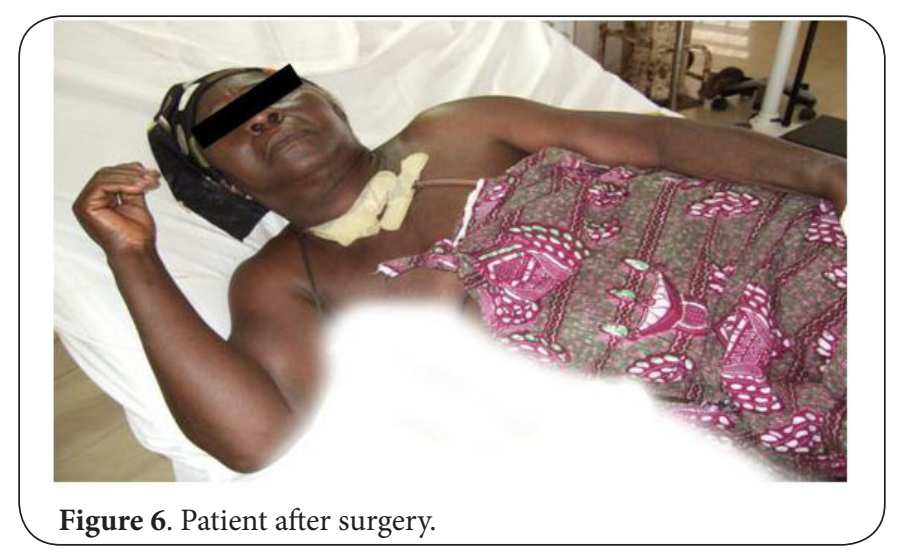

Thyroidectomy in such difficult circumstances is associated with difficulties in airway management during and after surgery. Some of these difficulties are due to trachea obstruction, tracheomalacia and injuries to the vocal cords. Difficult airway management is of paramount priority to the anaesthestist and also to the surgeon. Failure to oxygenate or ventilate the patient's lungs during anaesthesia will quite rapidly and predictably lead to brain damage or death. Prudent airway management during and after surgery is required to reduce mortality during surgery. Comorbid conditions and some patient characteristics such as laryngeal edema, anterior neck swellings, short neck and obesity may further aggravate the airway difficulties. In such circumstances difficulty in intubation is to be expected $[\mathbf{6 , 1 1}]$. Significant increase in incidence of difficulty in endotracheal intubation in patients presenting with Mallampati class 3/4 airway and neck mobility less than $90^{\circ}$ has been demonstrated during thyroid surgeries [10]. Our circumstance was in line with this finding as the patient presented with Mallampati grade 4 and restricted neck mobility during preoperative anaesthestic assessment.

The extent of airway distortion, couple with the fact that patient had history of failed intubation necessitated the need for proper planning of airway management in this case. These methods were appropriately planned, discussed with patient and informed consent obtained.

During induction of anaesthesia, both blind intubation methods using the gum elastic bougie and fibroptic technique had earlier failed due to severely deviated airways. Flexible fibreoptic intubation is usually considered as the gold standard in patients of this kind [12] but it was not possible in this patient. Relying on a LMA would be risky because there is bound to be a compromise of the already compressed airway during surgery. Moreover, the LMA will predispose the patient to aspiration during surgery. The procedure used to intubate and secure the airway was innovated to ensure that the surgery went well without respiratory complications. The option of tracheostomy gave us-controlled access to secure the airway during and after surgery. Tracheostomy is not commonly performed in most hospitals in developing countries even when there are indications for the procedure. On rare occasions when tracheostomy is performed it is usually on those who do not have anterior neck swellings. The sad reality is that patients who present with huge anterior neck swellings with severe airway deviations are usually left to their fate. The gold standard for patients presenting with severe airway deviation and narrowing is flexible fibreoptic intubation technique, an instrument which is not readily available to most hospitals in developing countries. Tracheostomy is the last resort in cases where fibreoptic intubation is not possible. However, tracheostomy is an invasive procedure and the expertise and experience with the procedure are still lacking in most of these hospitals. Also the anatomy of the anterior neck in many patients with huge multinodular goitres are distorted.

However, with proper planning between the anaesthetists and the surgeons the procedure can safely be performed in most of these hospitals to save the lives of patients who usually present late with life threatening multinodular goitres resulting in airway compressions and deviations.

In the index case the procedure was performed safely with neither intraoperative nor postoperative surgical or anaesthetic complication. Tracheostomy for huge multinodular goitres could be quite challenging, especially the highly vascularized goitres. With proper patient selection, adequate experience in goitre surgery, and the presence of skillful anaesthesiologist, tracheostomy is a procedure that could be considered in the circumstances where there is lack of advanced anaesthetic instruments to provide anaesthesia for patients presenting with severe airway deviation and or narrowing.

\section{Conclusion}

Airway management for thyroidectomy involving large goiters with severely compromised airways could be considered for tracheostomy in most hospitals in developing countries where advanced anesthesia equipments are not readily available.

\section{Competing interests}

The authors declare that they have no competing interests. 
Iddrisu Baba et al. Journal of Anesthesiology \& Clinical Science 2014, http://www.hoajonline.com/journals/pdf/2049-9752-3-4.pdf

\section{Authors' contributions}

\begin{tabular}{|l|c|c|c|c|c|c|c|c|c|}
\hline Authors' contributions & YI & AA & SW & MM & AR & YJ & PN & SK & JB \\
\hline $\begin{array}{l}\text { Research concept and } \\
\text { design }\end{array}$ & $\checkmark$ & $\checkmark$ & -- & -- & -- & -- & -- & -- & $\checkmark$ \\
\hline $\begin{array}{l}\text { Collection and/or } \\
\text { assembly of data }\end{array}$ & $\checkmark$ & -- & -- & -- & -- & -- & -- & -- & -- \\
\hline $\begin{array}{l}\text { Data analysis and i } \\
\text { nterpretation }\end{array}$ & $\checkmark$ & -- & $\checkmark$ & -- & $\checkmark$ & -- & -- & -- & $\checkmark$ \\
\hline $\begin{array}{l}\text { Writing the article } \\
\text { Critical revision of the } \\
\text { article }\end{array}$ & $\checkmark$ & -- & -- & -- & -- & -- & -- & -- & -- \\
\hline Final approval of article & $\checkmark$ & -- & -- & -- & -- & -- & -- & -- & - \\
\hline
\end{tabular}

\section{Acknowledgement}

We thank the main theatre nursing staff Tamale Teaching Hospital especially Jemilatu Alhassan Nagumsi, Aziz Adam and Emilia Salifu for their support during the perioperative period. We also thank INTERPLAST for their immense contribution toward the surgery.

\section{Publication history}

Editors: Narasimhan Jagannathan, Northwestern University, USA. Dario Galante, University Hospital Ospedali Riuniti of Foggia, Italy. Maria Matuszczak, University of Texas Medical School, USA.

EIC: D. John Doyle, Case Western Reserve University, USA.

Received: 28-Mar-2014 Final Revised: 30-Apr-2014

Accepted: 05-May-2014 Published: 16-May-2014

\section{References}

1. Delange F. The disorders induced by iodine deficiency. Thyroid. 1994; 4:107-28. I Article I PubMed

2. Hetzel BS. lodine deficiency: a global problem. Med J Aust. 1996; 165:28-9. I PubMed

3. McLaren EH and Alexander WD. Goitrogens. Clin Endocrinol Metab. 1979; 8:129-44. | PubMed

4. Rumstadt B, Klein B, Kirr H, Kaltenbach N, Homenu W and Schilling D. Thyroid surgery in Burkina Faso, West Africa: experience from a surgical help program. World J Surg. 2008; 32:2627-30. | Article I PubMed

5. Caplan RA, Posner KL, Ward RJ and Cheney FW. Adverse respiratory events in anesthesia: a closed claims analysis. Anesthesiology. 1990; 72:828-33. | Article | PubMed

6. Farling PA. Thyroid disease. Br J Anaesth. 2000; 85:15-28. | Article | PubMed

7. Benumof JL. Management of the difficult adult airway. With special emphasis on awake tracheal intubation. Anesthesiology. 1991; 75:1087110. | Article | PubMed

8. Apfelbaum JL, Hagberg CA, Caplan RA, Blitt CD, Connis RT, Nickinovich DG, Benumof JL, Berry FA, Bode RH, Cheney FW, Guidry OF and Ovassapian A. Practice guidelines for management of the difficult airway: an updated report by the American Society of Anesthesiologists Task Force on Management of the Difficult Airway. Anesthesiology. 2013; 118:251-70. | Article | PubMed

9. Mason RA and Fielder CP. The obstructed airway in head and neck surgery. Anaesthesia. 1999; 54:625-8. | Article I PubMed

10. Bouaggad A, Nejmi SE, Bouderka MA and Abbassi O. Prediction of difficult tracheal intubation in thyroid surgery. Anesth Analg. 2004; 99:603-6. | Article I PubMed

11. Lacoste L, Gineste D, Karayan J, Montaz N, Lehuede MS, Girault M, Bernit AF, Barbier J and Fusciardi J. Airway complications in thyroid surgery. Ann Otol Rhinol Laryngol. 1993; 102:441-6. I PubMed

12. Dabbagh A, Mobasseri N, Elyasi H, Gharaei B, Fathololumi M, Ghasemi M and Chamkhale IB. A rapidly enlarging neck mass: the role of the sitting position in fiberoptic bronchoscopy for difficult intubation. Anesth Analg. 2008; 107:1627-9. | Article | PubMed

\section{Citation:}

Iddrisu Baba Y, Adam A, Wilfred S-A, Mohammed Ibrahim M, Reith A, Jacob Bagviel Y, Nguyen PD, Kampo S and Benogle Ziem J. Perioperative airway management in the case of severe tracheal narrowing and deviation caused by multinodular goitre: case report. J Anesthesiol Clin Sci. 2014; 3:4. http://dx.doi.org/10.7243/2049-9752-3-4 